\title{
Initial Evidence for Increased Weather Salience in Autism Spectrum Conditions
}

\author{
MATTHEW J. BOLTON \\ College of Arts and Sciences, Saint Leo University, Saint Leo, Florida \\ WILLIAM G. BLUMBERG \\ School of Meteorology, University of Oklahoma, Norman, Oklahoma \\ LARA K. AULT \\ College of Arts and Sciences, Saint Leo University, Saint Leo, Florida \\ H. MichaEL MOGIL \\ How The Weatherworks, Naples, Florida \\ STACIE H. HANES \\ National Weather Service Weather Forecast Office, Gray, Maine
}

(Manuscript received 4 September 2018, in final form 15 August 2019)

\begin{abstract}
Weather is important to all people, including vulnerable populations (those whose circumstances include cognitive processing, hearing, or vision differences; physical disability; homelessness; and other scenarios and factors). Autism spectrum conditions affect information processing and areas of neurological functioning that potentially inhibit the reception of hazardous weather information and are of particular concern for weather messengers. People on the autism spectrum tend to score highly in tests of systemizing, a psychological process that heavily entails attention to detail and revolves around the creation of logical rules to explain things that occur in the world. This article reports the results of three preliminary studies examining weather salience-psychological attention to weather-and its potential relationships with systemizing in autistic people. Initial findings suggest that enhanced weather salience exists among autistic individuals relative to those without the condition and that this may be related to systemizing. These findings reveal some possible strategies for communicating weather to autistic populations and motivate future work on a conceptual model that blends systemizing and chaos theory to better understand weather salience.
\end{abstract}

\section{Introduction}

Weather impacts everyone, whether or not people notice. Impacts can be psychological and/or physiological, on both small and large scales. At the individual level, people often find their mood influenced by weather; may fear lightning, tornadoes, and the potential destruction wrought by these and other dangerous meteorological phenomena; account for the effects of heat and cold through clothing choice; ascribe mentalistic states (i.e., thoughts, feelings, and intentions) to weather; and seek to

Corresponding author: Matthew Bolton, matthew.bolton@ email.saintleo.edu enjoy weather's myriad forms of beauty. Beyond the individual, weather affects city, state, and national economies; regional and national infrastructures; transportation; politics; military decisions; and almost every aspect of modern society. Because of weather's significant impact, the U.S. National Weather Service (NWS) launched the Weather-Ready Nation (WRN) initiative in 2012. WRN endeavors to develop more effective methods of meteorological communication for dissemination to the general public and throughout the weather enterprise, and to increase both the quality and quantity of weather safety outreach efforts that help all people.

WRN-conscious meteorologists have taken steps toward greater inclusion in weather messaging for vulnerable 
populations (e.g., those with cognitive processing, hearing, or vision differences, and who are physically disabled). Color vision differences are now better accommodated (Bolton and Mogil 2018) and emergency managers typically work with those who are physically disabled and those who may be homeless (Reeb 2017). The NWS has considered the deaf and hard of hearing in lightning safety messaging since 2016 (National Weather Service 2016), and work (e.g., Sherman-Morris and Pechacek 2018) involving blind and low-vision populations is in its infancy. However, individual differences of a neurological nature (i.e., disabilities and conditions) have been difficult to incorporate into formal discussion.

One reason for this challenge is that no empirical weather-psychology work has considered people on the autism spectrum. Only hypotheses suggesting that autistic individuals might exhibit greater levels of physiological and psychological weather sensitivity when compared with nonautistic individuals have been put forward (Bolton et al. 2017). Hence, the overarching goal of this paper is to extend the integrated weatherpsychology intersection via a three-study exploration, and discussion of relationships between weather salience and autism, in order to support and encourage future WRN efforts focused on neurologically diverse populations. We anticipate lessons learned from work in this area might also extend to benefit neurotypical populations. We aim here to begin building a theoretical base from which future applied work may draw insight and provide some initial advice for how said theory may start to be applied. This paper will next discuss some key characteristics of autism and the theoretical concepts of systemizing and weather salience. Section 3 will then detail the methods used to examine our empirical questions. Section 4 will provide the study results, and section 5 will, discuss these results and their potential future theoretical and practical implications.

\section{Background}

\section{a. Autism}

Occurring in 1 in 59 individuals and affecting some 3.5 million people in the United States (Buescher et al. 2014; U.S. Centers for Disease Control 2018), autism is a heterogeneous set of neurological conditions existing along a continuous spectrum. Autism is characterized by difficulties in social communication, unusually narrow interests and repetitive behaviors, and sensory sensitivities (American Psychiatric Association 2013). Autistic people typically have varying degrees of functional and support needs, and different individuals will either have more or less relative to each other. Areas of strength and weakness may exist simultaneously for these individuals (e.g., some autistic people may have severe anxiety but function well in other ways). See Baron-Cohen (2017) and Masi et al. (2017) for further discussion. The empathizing-systemizing (E-S) theory attempts to explain autism's social and nonsocial behaviors, including attention to detail and a psychological need for sameness and structure (Baron-Cohen 2009). The theory provides a foundation for understanding weather salience (psychological attention to weather) in autistic populations via detail orientation and pattern recognition.

\section{b. Systemizing}

E-S theory states that autistic individuals are stronger in systemizing than people in the general population, at the expense of cognitive empathizing (Baron-Cohen et al. 2003) [for evidence, see, e.g., Wheelwright et al. (2006), Kidron et al. (2018), Svedholm-Häkkinen and Lindeman (2016), and Warrier et al. 2019]. Empathy is cognitive and affective, involving the ability and drive to imagine another person's mental states (their thoughts, intentions, desires, and feelings) and to respond to mental states with an appropriate emotion. Empathy is typically stronger in women (Baron-Cohen and Wheelwright 2004; Baez et al. 2017), and men appear to be strongest in systemizing (e.g., Baron-Cohen et al. 1986, 2001a, 2003; Lawson et al. 2004; Wheelwright et al. 2006; Kidron et al. 2018).

Systemizing, viewed in E-S theory as empathy's opposite, is the drive and ability to identify and formulate psychological systems, which are sets of logical rules one uses to explain the workings of the physical world. Researchers view empathizing and systemizing as innate cognitive styles-frameworks for the way people think, gather, process, use, and remember information (Kozhevnikov 2007). Some people are stronger in empathizing while others are more naturally oriented toward systemizing; still others possess a more balanced cognitive profile (Baron-Cohen 2003).

Systems follow linear, predictable patterns that start with an input, go through an operation, and end with a reliable output. A light switch is a simple example. The switch is the input that, when flipped, produces an operation involving electrical current; the resulting light that either enters into or is removed from the environment is the output. This logical, if-then principle extends so that any lawful information can be systemized. Six primary kinds of systems were theorized (abstract, mechanical, collectible, motoric, social, and natural; see Baron-Cohen 2003, 2006). Natural systems are particularly relevant to this paper.

Systemizing occurs when a person observes some individual system part or detail and then monitors the overall system for lawful change. The individual may 
passively observe the system or engage with its constituent parts to determine the system's predictability (Baron-Cohen 2003). Ideal systemizing involves keeping everything constant and changing only one parameter at a time, so that each small change can be observed relative to the overall system. This allows for the verification of predictability through an understanding of sensitivity (Baron-Cohen et al. 2009). Systemizing works so that as one's cognitive profile leans toward attention to detail and repetitive pattern seeking increases-as one's drive to systemize increases-then the need for systems of lower variance also increases, to the point of hypersystemizing (Baron-Cohen 2006). Hypersystemizers favor psychological systems of little to no variance (e.g., a light switch or times tables in math).

The repetitive behavioral patterns occurring during the autistic systemizing process lead between $75 \%$ and $95 \%$ of autistic people (Bashe and Kirby 2001; Klin et al. 2007; Turner-Brown et al. 2011) to become highly passionate for, and possibly develop specialized knowledge in, "special interests." Research and anecdotal evidence suggests not only that weather is one such interest (Baron-Cohen 2006; Grove et al. 2018; Mancil and Pearl 2008; CBC News 2013; Gartner 2014; Newman 2014), but that these begin to develop in autistic children between the ages of 1 and 4 (Attwood 2003; Bashe and Kirby 2001; Moore and Goodson 2003) and are commonly aligned with similar systemizable domains (BaronCohen 2006; Jordan and Caldwell-Harris 2012; Fells 2013; Caldwell-Harris and Jordan 2014; Grove et al. 2018).

How do people with autism spectrum conditions (ASC) systemize the weather? Some autistic people may ask over and over, day after day, what the weather will be-even when they know the forecast (S. Baron-Cohen 2018, personal communication; our anecdotal interactions with autistic individuals and correspondence with parents of autistic people). Such behavior may help to soothe a psychological need for routine and sameness and/or occur because pleasure is derived from learning and knowing the answer (Baron-Cohen 2006). Others may be driven, for example, to memorize the cloud types, or they might monitor daily weather patterns and research and compile archives of historical analogs to current conditions. These actions may help to improve individuals' self-concept of weather predictability or help to offset fear brought on by its apparent unpredictability by giving them a feeling of control.

There are many positive benefits of systemizing that may extend into the weather domain. The drive to study the weather through systemizing may involve a brain-behavior cycle in which the repetitive behavior trains, in a sense, the individual's perceptual processing system to a point of expertise (Mottron et al. 2006).
Given evidence for enhanced perceptual salience and attention to detail in autism (e.g., Caron et al. 2006; Dakin and Frith 2005; Jarrold et al. 2005; Joseph et al. 2009; Keehn et al. 2012; O'Riordan et al. 2001; O'Riordan 2004; Plaisted et al. 1998), systemizing may work as a cognitive mechanism that strengthens perceptual salience, the degree to which something is noticeable to people (Stokols 1985; Taylor and Fiske 1979), when physically observing weather phenomena. Systemizing may thus allow meteorological features such as those observed in cloud observation or on weather maps (e.g., cold fronts), to "pop out" visually to the individual. Systemizing appears to aid the development of talent (Pring et al. 1995; Mottron et al. 1996; Heavey et al. 1999; Happé 1999; Pring and Hermelin 2002; Happé and Frith 2006; Happé and Vital 2009; Heaton 2009; Drake et al. 2010), and appears not only linked to interest in science (Zeyer et al. 2012) but to be a predictor of entrance into science, technology, engineering, and mathematics fields (Billington et al. 2007; Kidron et al. 2018). Corroborating this is the finding that autistic traits are common in engineers, mathematicians, and physicists (Baron-Cohen et al. 1997, 1998, 1999, 2001b) and among meteorologists (Bolton et al. 2018a). Researchers have extensively investigated potential linkages between autism, systemizing, and science (Baron-Cohen et al. 2007; Baron-Cohen 2015; Bolton et al. 2018b; Roelfsema et al. 2011; Ruzich et al. 2015; Wheelwright and Baron-Cohen 2001). These links motivate our interest in using the concept of weather salience to understand how autistic populations engage with weather.

\section{c. Weather salience}

Weather salience is "the degree to which individuals attribute psychological value or importance to the weather and the extent to which they are attuned to their atmospheric environments" (Stewart 2009, p. 1833). In assessing weather salience empirically and in discussing its theoretical underpinnings, Stewart drew on concepts from environmental psychology. These concepts are perceptual salience; valence, the extent to which weather events induce a (good or bad) emotional response (Campbell 1983); duration and periodicity, weather's significance based on its variability and predictability (Evans and Cohen 1987); and psychological and emotional attachment, for just as people can become attached to geographical locations (Altman and Low 1992), so too can an individual become attached to different kinds of weather (Knez 2005). Epistemic (informational) (Litman and Spielberger 2003) and perceptual curiosity (Stewart 2017) and knowledge (Stewart 2009; Stewart et al. 2012) also play roles in weather salience. 


\section{Methods}

This paper discusses three mixed-methods studies of weather salience (henceforth S1, S2, and S3, with sample sizes of 303, 187, and 263 individuals, respectively) that examined between-group (autistic/nonautistic) differences in weather salience and the relationships between weather salience, autistic traits, and systemizing. Given the anecdotal evidence for heightened weather interest in autism, autistic individuals were hypothesized to have greater weather salience than nonautistic individuals. Because this work was exploratory, no other hypotheses were specified. Four survey instruments were used in this work.

First, the "Weather Salience Questionnaire" (WxSQ; Stewart 2009) was used to measure weather salience. This is a 29-item, 5-point Likert-scale questionnaire that measures across several dimensions including attention to weather, weather sensing and direct observation of weather, effects of weather on daily activities, attachment to weather patterns, effects of weather on mood, need for weather variability, and attention to weatherinduced holidays. S1 and S2 used the full, 29-item version; S3 used only the weather attention and sensing and observing subscales. All three WxSQ scores were reliable according to the Cronbach $\alpha$ (alpha) reliability statistic $^{1}$ (S1: 0.84; S2: 0.83; S3: 0.76).

The S3 attention-based scores were initially unreliable $(\alpha=0.42)$. Three of the 13 items $(6,7$, and 8 in the original scale) were identified via correlational analysis as having little relatability to the remaining items, possibly due to their social and introspective nature. Interpretation by the autistic participants may have been affected by the items negative phrasing, differential item functioning issues (Agelink van Rentergem et al. 2019) and the introspection (Silani et al. 2008) and social difficulties in autism. Removing these items did not negate the scale's attention-based validity and yielded a higher reliability based on the remaining 10 items.

Next, we used the 50-item Autism-Spectrum Quotient (AQ; Baron-Cohen et al. 2001b) and 25- and 18-item versions of the Systemizing Quotient (SQ; Wakabayashi et al. 2006; Ling et al. 2009; Wheelwright et al. 2006) to assess autistic traits and systemizing, respectively. These Likert-scale-based measures were used in S2 and S3. The AQ is a measure of autistic trait levels via behavioral tendencies related to social skills, need for routine, attention switching, imagination, and numbers/patterns. Both AQ scores were reliable (S2 at $\alpha=0.93$; S3 at $\alpha=0.95$ ).

\footnotetext{
${ }^{1}$ This statistic, ranging from 0 to 1 , estimates how internally consistent validated scale items are, that is, how well they assess the construct they were designed to measure (Cronbach 1951). Scores are generally considered to be reliable at alpha levels at/above 0.70 .
}

The SQ assesses interest in, or preference for, different types of systems. S2 $(\alpha=0.89)$ used a short version, and S3 $(\alpha=0.86)$ used a detail-orientation-focused version. These shorter versions lowered participant dropout and centered hypotheses more firmly on weather salience as we then understood it.

The Intuitive Physics Test (IPT; Baron-Cohen et al. 2001a) is a mechanical reasoning task in which respondents are presented with illustrations of gears and other machinery and asked to describe how they work, given a multiple-choice answer bank. S3 used 9 of 20 IPT items to measure systemizing ability's relationship to preference for attention-based systemizing and attentionbased weather salience. These items were not scored with the $\alpha$ measure because reliability in this context only applies to questionnaires and not performance tasks.

\section{a. Participant recruitment}

Online Qualtrics surveys (approved by the Saint Leo University research ethics review board) were distributed for all three studies. Participant recruitment was through social media (e.g., Facebook, Twitter) and the Autism Society of Maine's website for S1. For S2 and S3, participants were recruited through social media and the Cambridge Autism Research Database (http://www.autismresearchcentre.com and http://www.cambridgepsychology.com). Specific site origin data are unavailable. Participants completed simple demographic questions (age, gender identity, and racial classification), the WxSQ, and/or AQ or SQ (depending on study). Study 1 and study 3 categorically measured (via a yes/no item) weather interest and interest in becoming a meteorologist, while study 2 examined selfperceived interest in weather and science via single-item Likert scales. Tables 1 and 2 and Fig. 1 summarize the participants' racial and gender classifications across all three studies and across the groups (autism/no-autism). The S1 participants ranged in age from 18 to 68 (mean $M=28.71$; standard deviation SD = 10.23); for S2 the range went from 18 to $72(M=29.88$; $\mathrm{SD}=11.49)$; and for $\mathrm{S} 3$ it went from 18 to $89(M=45.84 ; \mathrm{SD}=15.65)$. The $\mathrm{S} 1$ autistic participants ranged in age from 18 to 68 with a mean of 28.35 ( $\mathrm{SD}=9.94)$; $\mathrm{S} 1$ nonautistic participants ranged from 18 to 64 with a mean of $30.13(\mathrm{SD}=10.94)$. The $\mathrm{S} 2$ autistic participants ranged in age from 18 to 54 with a mean of 27.44 ( $\mathrm{SD}=8.07) ; \mathrm{S} 2$ nonautistic participants ranged from 18 to 72 with a mean of $33.94(S D=14.83)$. The S3 autistic participants ranged in age from 18 to 75 with a mean of 44.21 ( $\mathrm{SD}=14.45)$; S3 nonautistic participants ranged from 18 to 89 with a mean of $49.02(S D=17.42)$.

\section{b. Data analysis plan}

Nonbinary participants (those identifying as neither male or female) were removed because there were not 
TABLE 1. Breakdown of participants' racial classification by study.

\begin{tabular}{|c|c|c|c|c|c|}
\hline Caucasian & Asian & African-American & Hispanic & Latino/a & Other \\
\hline \multicolumn{6}{|c|}{ S1 participants } \\
\hline $260(85.8 \%)$ & $8(2.6 \%)$ & $6(2 \%)$ & $5(1.7 \%)$ & $2(0.07 \%)$ & $22(7.3 \%)$ \\
\hline \multicolumn{6}{|c|}{ S2 participants } \\
\hline \multicolumn{6}{|c|}{ S3 participants } \\
\hline
\end{tabular}

enough of these individuals in any study to make fair statistical comparisons with the recruited men and women. In addition, outlying scores of \pm 2 standard deviations were removed from the datasets, and only S1 participants who fully reported age and gender identity-and age, gender identity, and country for S2 and S3 - were included in analyses. This filtering was performed so that only participants who fully completed the survey were included in the following two-step analysis procedure.

First, Welch's analysis of variance ${ }^{2}$ (ANOVA) was used to examine between-group differences in weather salience and systemizing across all three studies. S2 differed from S1 by examining, via correlational analysis, the relationships between age, weather salience (WxSQ), systemizing preference (SQ), and autistic traits (AQ), whereas $\mathrm{S} 3$ examined these same variables while adding systemizing ability (IPT performance), and selfreported interest in both science and weather.

Effect sizes (eta-squared $\eta^{2}$, for Welch's ANOVA), 95\% confidence intervals $(\mathrm{CI})$, and statistical power were then calculated to assess the strength of our results. Effect sizes, ranging from 0 to 1 , measure the amount of standardized difference between means (Levine and Hullett 2002), while confidence intervals here estimate the range in which the value of the particular variable could be expected to fall if a study were conducted multiple times with the same sample size drawn from the same population (Boslaugh 2012). Power is a measure, also ranging from 0 to 1 , that represents the probability of correctly detecting a true effect in the form of mean difference scores (Boslaugh 2012).

\section{Results}

First, significant group differences were determined for systemizing in S2 and S3, replicating previous work on systemizing in autism such that the sampled autistic individuals expressed the trait more highly than the

\footnotetext{
${ }^{2}$ Chosen because of unequal variance in the $\mathrm{S} 1$ and $\mathrm{S} 2$ samples and recent recommendations (Delacre et al. 2019) that it is more robust to variance differences and a better option overall than the regular $F$-test ANOVA.
}

sampled neurotypical individuals. For S2, $F(1,124.47)=$ $5.45\left(M_{\text {Autism }}=25.81\right.$ with SD $=9.86$ and $\mathrm{CI}=[23.84$, 27.77]; $M_{\text {Comparison }}=22.12$, with $\mathrm{SD}=9.37$ and $\mathrm{CI}=$ [19.66, 24.58]), $p=0.021, \eta^{2}=0.13$, and power $=0.37$. For S3, the difference was $F(1,130.49)=4.38\left(M_{\text {Autism }}=\right.$ 17.75 , with $\mathrm{SD}=7.15$ and $\mathrm{CI}=[16.55,18.96] ; M_{\text {Comparison }}=$ 15.40 , with $\mathrm{SD}=8.01$ and $\mathrm{CI}=[13.52,17.29]), p=0.038$, $\eta^{2}=0.02$, and power $=0.56$.

The autistic participants in all studies were nonsignificantly higher in weather salience, therefore supporting our core hypothesis for these studies. For S1, Welch's $F(1,106.118)=1.32\left(M_{\text {Autism }}=98.93\right.$, with $\mathrm{SD}=16.99$ and $\mathrm{CI}=[96.50,101.36] ; M_{\text {Comparison }}=$ 95.97, with $\mathrm{SD}=18.37$ and $\mathrm{CI}=[91.45,100.49]), p=$ $0.254, \eta^{2}=0.007$, and power $=0.26$. For S2, Welch's $F(1,126.79)=0.395\left(M_{\text {Autism }}=64.16\right.$, with SD $=16.30$ and $\mathrm{CI}=[60.94,67.38] ; M_{\text {Comparison }}=62.55$, with $\mathrm{SD}=$ 15.06 and $\mathrm{CI}=[58.59,66.51]), p=0.531, \eta^{2}=0.003$, and power $=0.10$. For S3, Welch's $F(1,205)=0.300$

TABLE 2. Breakdown of participants' racial classifications by group (autism/no autism).

\begin{tabular}{|c|c|c|}
\hline & Autism & No autism \\
\hline & \multicolumn{2}{|c|}{$\mathrm{S} 1$} \\
\hline Caucasian & $183(83.9 \%)$ & $77(90.6 \%)$ \\
\hline Asian & $4(1.8 \%)$ & $4(4.7 \%)$ \\
\hline African-American & $6(2.8 \%)$ & \\
\hline Hispanic & $5(2.3 \%)$ & \\
\hline Latino/a & $2(0.09)$ & \\
\hline \multirow[t]{2}{*}{ Other } & $18(8.3 \%)$ & $4(4.8 \%)$ \\
\hline & \multicolumn{2}{|c|}{$\mathrm{S} 2$} \\
\hline Caucasian & $103(88 \%)$ & $59(84.3 \%)$ \\
\hline Asian & & $4(5.7 \%)$ \\
\hline African-American & $2(1.7 \%)$ & \\
\hline Hispanic & $1(0.09 \%)$ & $2(2.9 \%)$ \\
\hline Latino/a & $1(0.09 \%)$ & $1(1.4 \%)$ \\
\hline \multirow[t]{2}{*}{ Other } & $10(8.2 \%)$ & $4(5.7 \%)$ \\
\hline & \multicolumn{2}{|c|}{ S3 } \\
\hline Caucasian & $164(94.3 \%)$ & $77(86.5 \%)$ \\
\hline Asian & $3(1.7 \%)$ & $3(3.4 \%)$ \\
\hline \multicolumn{3}{|l|}{ African-American } \\
\hline Hispanic & & $3(3.4 \%)$ \\
\hline Latino/a & $1(0.06 \%)$ & $1(1.1 \%)$ \\
\hline Other & $6(3.4 \%)$ & $5(5.6 \%)$ \\
\hline
\end{tabular}



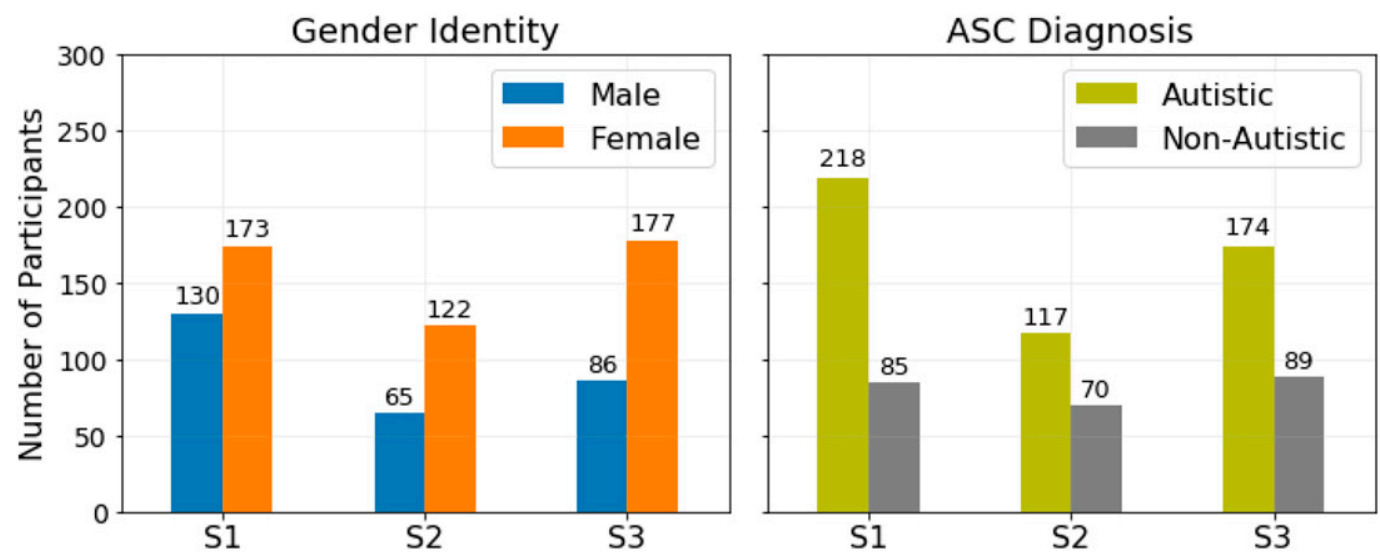

FIG. 1. Breakdown of gender and group participants by study.

$\left(M_{\text {Autism }}=39.07\right.$, with SD $=7.25 ; M_{\text {Comparison }}=37.97$, with SD $=7.71), p=0.584, \eta_{p}^{2}=0.001$, and power $=0.09$.

\section{a. Differences in weather interest}

Findings persisting across both S1 and 3 were higher self-reported general interest in weather, and a greater desire to become meteorologists, among the recruited autistic individuals. S1's interest in weather question had 111 "yes" responses. Of these, 72.97\% $(n=81)$ were from autistic individuals. The question assessing desire to become meteorologists had 36 "yes" responses, 31 of which were from autistic individuals.

In S3, out of 167 responses from the autistic group, $70.43 \%(n=81)$ were "yes" responses on the weather interest item compared with $29.57 \%(n=25 / 91)$ of the nonautistic group. A "yes" response to the meteorologist item was provided by $22.60 \%(n=17 / 75)$ of the autistic group compared to $15 \%(n=3 / 32)$ of the nonautistic group. In S2, self-reported science interest was similar between groups $\left(M_{\text {Autism }}=7.82\right.$, with $\mathrm{SD}=2.31 ; M_{\text {Comparison }}=7.26$, with $\mathrm{SD}=2.40$ ), whereas the autism group was lower in weather interest $\left(M_{\text {Autism }}=5.97\right.$, with SD $=2.57 ; M_{\text {Comparison }}=$ 6.28 , with $\mathrm{SD}=2.63$ ). Given the small sample and number of other tests conducted, we did not test this comparison statistically.

An open-ended response question assessed what, if anything, S1 and S3 participants liked about weather. An inductive qualitative theme analysis (Braun and Clarke 2006) was performed on the data, which ranged from single words to detailed paragraphs. Table 3 showcases a selection of these and Table 4 their distribution. Five themes emerged in our analysis:

1) beauty, including appreciation of weather, wonder at its power, awe, and other intense positive emotions associated with enjoying the experience of weather;
2) fear, involving comments about storms, unpredictability, confusion about weather, or being scared or overwhelmed by weather;

3) complexity, involving liking how much weather changes, interest in systems, fascination with complex patterns, and variety in weather;

4) science, involving comments about clouds, radar, forecasting, weather-related science, geography, temperature, humidity, and related meteorological variables; and

5) physical effects, involving positive or negative experience of the weather physically or from a sensory standpoint.

Across both studies, the overarching theme that emerged, especially for autistic responses, was the notion of weather as a predictable and/or categorical system. Autistic participants also wrote considerably more about why they liked weather than those without autism. Among both groups, complexity and science were the most common themes, with autistic participants mentioning complexity slightly more often than science, and neurotypical participants mentioning science slightly more often than complexity. Fear was surprisingly low, with few participants indicating it as a part of their weather interest. Physical experiences were mentioned less than expected as well, but more by those on the spectrum ( $11 \%$ as opposed to $1 \%$ of respondents) in study 2 only. Excepting fear, in both studies, autistic participants wrote at least twice as much in each category than those without autism. This pattern might indicate autistic people have thought more about weather and have more interest in describing their experiences in detail compared to neurotypical people. It is unclear why there were such differences between the two studies; these may be explained by sampling and survey distribution methods, and also by differences inherent to each study population. 
TABLE 3. Example comments from qualitative theme analysis by group (autism/no autism): what participants like about weather.

\begin{tabular}{|c|c|}
\hline Autistic & Nonautistic \\
\hline $\begin{array}{l}\text { "I love it when interesting formations that make dramatic sunsets. I } \\
\text { have painted them on occasion. I love snow when it falls in big heavy } \\
\text { flakes and covers the ground quickly. It makes every look so clean, } \\
\text { roads in particular. I enjoy seeing a hard frost make everything look } \\
\text { like everything is covered in icing sugar. It's especially beautiful } \\
\text { when frost coloured trees contrast with a clear blue sky. I enjoy the } \\
\text { routine of looking at the BBC weather app every morning. It has to } \\
\text { be that particular app. It's good to listen to hard rain or strong wind } \\
\text { when I'm tucked up warm inside. When the country experiences } \\
\text { flooding it reminds me how small we are as humans against the huge } \\
\text { elements of nature." (S3) }\end{array}$ & $\begin{array}{l}\text { "Just like knowing what to expect" (S1) } \\
\text { "Constant change. Plus, it really is a topic of conversation } \\
\text { amongst Canadians. Can't get through a single small talk } \\
\text { conversation without the weather being addressed. Plus, the } \\
\text { weather is just neat. So many processes all interacting to } \\
\text { create something that impacts us all." (S3) }\end{array}$ \\
\hline $\begin{array}{l}\text { "How the sky looks. The predictable yet unpredictable aspect to } \\
\text { nature in the sky. It brings a sense of calm in chaos for me." (S1) } \\
\text { "Ummm this is a big question. I personally like the sun and snow and } \\
\text { sound of the wind but don't like rain and wet ground but on a bigger } \\
\text { level what I like about the weather is weather means life...the sun to } \\
\text { grow, the rain the water and the wind to pollinate etc." (S3) }\end{array}$ & $\begin{array}{l}\text { "The play of light in the sky and across the landscape. The } \\
\text { endless variety of the clouds. The effect of the wind and rain } \\
\text { on the plants. The warmth of the sun." (S3) }\end{array}$ \\
\hline $\begin{array}{l}\text { "I like to know ahead of time how humid it will be. I also like to know } \\
\text { when it will be cold because it will hurt my joints badly. I like to } \\
\text { know when I will be comfortable (between about 70-85, low } \\
\text { humidity only)." (S3) }\end{array}$ & $\begin{array}{l}\text { "The fact it changes. The light and colours. The drama of it. The } \\
\text { way it can change or enhance your mood." (S3) }\end{array}$ \\
\hline $\begin{array}{l}\text { "This planet's weather is fascinating. Often I watch it, feel it, listen to } \\
\text { it, smell it, all the while in awe of the fact that whether mankind was } \\
\text { here or not, or in fact any living thing, the weather would be just the } \\
\text { same-gas currents flowing over a barren, alien terrain. We live in a } \\
\text { bubble, seeing blue skies, fluffy white clouds, warm summer breezes } \\
\text { rustling the trees. I find myself always looking through this veneer at } \\
\text { the cosmic reality. Through the thin veil of gas and water vapour } \\
\text { gently enveloping, what would otherwise be a barren rock. Being } \\
\text { constantly aware of this means I can't switch off and rest. In another } \\
\text { breath, I sail in coastal waters and so have a very great interest in } \\
\text { weather forecasts and the importance of accuracy. I'm also aware of } \\
\text { just how difficult it is to model weather systems, including local } \\
\text { effects such as katabatic \& anabatic winds. I like weather for its life } \\
\text { supporting properties, for its ambivalence to any living thing on this } \\
\text { planet." (S3) }\end{array}$ & $\begin{array}{l}\text { "Everything. I live in the UK so there are never two days the } \\
\text { same. It is constantly changing. We discuss it all the time and, } \\
\text { as I live in the North East where we regularly talk to strangers } \\
\text { we meet, it is a great topic of conversation. I prefer the sun to } \\
\text { shine be it summer or winter, but I also love to hear rain } \\
\text { beating on my window. I adore snow but only if I can } \\
\text { withdraw inside." (S3) }\end{array}$ \\
\hline
\end{tabular}

\section{b. Correlations in $S 2$ and $S 3$}

Table 5 shows the correlations between the S3 variables, and the $\mathrm{S} 2$ correlations were as follows:

1) autistic traits and systemizing gave $r(145)=0.34$, with $p<0.000$;

2) autistic traits and weather salience gave $r(138)=-0.15$, with $p=0.081$;

3) systemizing and weather salience gave $r(141)=-0.24$, with $p=0.004 ;$ and

4) age and weather salience gave $r(157)=-0.023$, with $p=0.774$.

\section{Discussion}

Our sample sizes are fairly typical within the field of psychology, but the studies reported here were substantially lacking in participants and correspondingly lacked power to detect significant effects. Although group differences were nonsignificant, the autistic individuals were consistently higher than the neurotypical individuals in weather salience, confirming our primary hypothesis for increased weather salience among the autistic participants. This trend also extends across several S1 and S2 WxSQ dimensions (Tables 6 and 7) and therefore warrants further discussion. As expected based on the underlying difficulties and differences known to exist for individuals on the autism spectrum, S1 autistic participants reported greater impacts of weather on daily activities and mood (there was essentially no difference in S2). This could be for a multitude of reasons, including sensory sensitivities or co-occurring health conditions that limit or otherwise affect activity in particular weather situations, or severe weather anxiety or phobia [based on neurotypical weather anxiety research (e.g., Coleman et al. 2014) and work on 
TABLE 4. Percent of qualitative comments by group and study.

\begin{tabular}{lccc}
\hline & Autism & No autism \\
\hline & & $\mathrm{S} 1$ & \\
Beauty & $10 \%$ & & $2.60 \%$ \\
Fear & $1.80 \%$ & & $1.80 \%$ \\
Complexity & $32.50 \%$ & & $8.80 \%$ \\
Science & $29.80 \%$ & & $7.90 \%$ \\
Physical effects & $2.60 \%$ & & $1.80 \%$ \\
& & $\mathrm{~S} 3$ & \\
Beauty & 16.50 & & 5.50 \\
Fear & 2.70 & & 1.10 \\
Complexity & 20.90 & & 9.90 \\
Science & 23.10 & & 8.80 \\
Physical effects & 11.00 & & 1.10 \\
\hline
\end{tabular}

anxiety in autism, (e.g., Neil et al. 2016)]. The findings related to sensory differences and weather conditions warrant future research, as they could provide valuable insight to support individuals in need.

Taken together, in light of the rich anecdotal evidence for heightened autistic weather interest, our preliminary results provide the first empirical evidence for potential linkages between autism and weather-specifically, that weather salience is at least marginally higher in autistic than in typically developed individuals. In stating this, we acknowledge the nature of our nonsignificant results and the possibility of false positives. ${ }^{3}$ Yet, it is possible, given autism's vast heterogeneity, that differences in autistic weather salience are legitimate but small and variable. It is also important to note that our samples may have an amplified selection bias, whereby the autistic individuals who participated, already more weather salient, were more inclined to participate because of their higher salience and interest. Our participants were also presumed able to participate: The self-report nature of these studies would naturally inhibit some autistic people who are more functionally limited in their daily lives. Thus, these are not representative samples. Bearing all of this in mind, the discussion that follows provides a theoretical understanding of our findings as well as some advice for WRN communicators.

\section{a. An autism-systemizing-weather paradox}

Conceptually, the relationship between autism, systemizing, and weather salience presents an interesting paradox. The data presented here suggest the occurrence of enhanced weather salience in autism, potentially tied

\footnotetext{
${ }^{3}$ Relatively common in psychological science when attempting to identify meaningful findings that actually occur in the real world, since many studies are underpowered (Szucs and Ioannidis 2017).
}

to enhanced systemizing and increased autistic traits. However, just as there are autistic individuals with enhanced weather salience, weather salience may also be markedly lower for some autistic people, and this situation is also represented in our data.

In $\mathrm{S} 2$, we observed negative correlations between autistic traits and weather salience, and between weather salience and systemizing. This makes sense, theoretically, since autistic traits and increased systemizing behaviors impact daily life and functioning. Additionally, we found a positive correlation between autistic traits and systemizing drive. Autistic people who are inhibited more drastically in their daily lives (from a functioning standpoint) will likely not be as concerned about most day-to-day weather situations (unless there is a dangerous weather event, or perhaps if the individual has a strong weather phobia or high physiological sensitivity to weather and environmental changes). Meanwhile, S3 found a significant positive correlation between weather salience and autistic traits, but not between weather interest and autistic traits, while systemizing ability was only very weakly correlated with weather interest. On top of the S2 evidence, the weak link between autistic traits and weather interest in S3 suggests that while the drive to systemize weather may be strong in autism, actual systemizing ability cancels out, in some cases, the systemizing-weather connection and therefore can make weather less salient for some autistic people.

How, then, does systemizing manifest across the autism spectrum, and what might this mean for potential communication strategies that meet the individual's weather salience and interest levels? Systemizing is linked to autistic trait levels (e.g., Wheelwright et al. 2006; Warrier et al. 2019) and in the same way that autistic traits present differently for different people, systemizing behaviors and traits also differ from person to person. Many are linked to environmental factors-for example, some people may engage in a strong exhibition of motoric hypersystemizing by rocking back and forth or by flapping their hands (Baron-Cohen et al. 2009) — while other individuals may be driven to deep engagement with a hobby. Autistic individuals interested in numerical systems may have prodigious mathematical talent, or only be concerned about their daily schedules and keeping their routines on time (BaronCohen 2006). Some autistic people have enhanced accuracy in pitch processing (Heaton 2003, 2005) and discrimination (Bonnel et al. 2003, 2010), which can indicate an affinity for auditory environmental cues (Greenberg et al. 2015a,b). Socially-and this may occur in weather education settings-some autistic people may begin a sentence and then wait for another person 
TABLE 5. Correlations between age, weather salience, systemizing (both self-reported preference and performance task), autistic traits, and interest in both weather and science. Three asterisks $=p<0.001$; two asterisks $=p<0.05$.

\begin{tabular}{|c|c|c|c|c|c|c|c|}
\hline Variables & 1 & 2 & 3 & 4 & 5 & 6 & 7 \\
\hline 1: age & - & & & & & & \\
\hline 2: weather salience & $0.29^{* * * *}$ & - & & & & & \\
\hline 3: systemizing preference & $0.19^{* * *}$ & $0.43^{* * *}$ & - & & & & \\
\hline 4: autistic traits & $-0.17^{* *}$ & $0.15^{* *}$ & $0.20^{* *}$ & - & & & \\
\hline 5: systemizing ability & 0.03 & 0.11 & $0.32^{* * * *}$ & $0.17^{* *}$ & - & & \\
\hline 6: science interest & -0.03 & $0.28^{* * * *}$ & $0.55^{* * * *}$ & $0.20^{* *}$ & $0.34^{* * * *}$ & - & \\
\hline 7: weather interest & $0.35^{* * * *}$ & $0.56^{* * *}$ & $0.38^{* * * *}$ & 0.10 & 0.04 & $0.30^{* * * *}$ & - \\
\hline
\end{tabular}

in the conversation to finish it; others may insist that the same topics are discussed every time in an interaction (Baron-Cohen 2006). The possibilities are many.

These various manifestations reflect the heterogeneity of autism, and at least as much heterogeneity might be presumed to exist in autistic weather salience. Some people may be very salient and very interested, while others salient but not interested, and yet others perhaps interested but not very salient. This complexity inhibits the development of concrete communication rules for autistic individuals WRN can use. However, the acknowledgment of this diversity in characteristics and behaviors is a first step required for communicators to discover new ways to reach autistic populations.

\section{b. Systemizing chaos}

A broader question raised within this work may help the WRN communicators already aware of the difficulties inherent in weather prediction and messaging: How are chaotic dynamical systems perceived by those with various levels of systemizing drive and ability? Succinctly put, a chaotic system is one with an evolution that appears to be driven by random processes despite the fact that it is governed by nonstochastic processes (Lorenz 1993). Essentially, it is the chaotic system's sensitivity to initial conditions that helps create this illusion, and although such systems may behave with periodicity, useful predictions of the system evolution cannot always be obtained. A definition posited by Lorenz, as shared by Danforth (2015) summarizes chaos: "Chaos: When the present determines the future, but the approximate present does not determine the approximate future." Both weather and social systems can be considered as chaotic (e.g., Young 1995; Lorenz 1963, 1964, 1993; Guastello and Liebovitch 2009), and the theoretical intersection of systemizing and chaos may reveal ways to develop weather messaging strategies across multiple populations.

We hypothesize that the difficulties inherent to understanding chaotic systems, like those of the atmosphere, can either be amplified or eased by the degree of systemizing drive and ability an individual exhibits. Chaotic dynamic systems may be approximated as linear within short time frames and, therefore, can be systemized, because they are analyzed and can appear well behaved over a small increment (i.e., of time or space). This technique is often used in weather forecasting by extrapolating current conditions and trends. However, because of imperfect knowledge of the system/initial conditions and the system's sensitivity to the initial conditions, the systemizing strategy (generating tiny perturbations and observing the change) can fail when used to analyze chaotic systems - and can lead the individual to simply dismiss the system as random and therefore unpredictable. Each individual creates a subjective definition of what randomness or lawlessness is to them and therefore creates a personal characterization of different systems.

TABLE 6. Descriptive statistics for WxSQ subscales by group, from S1. For autism, $N=190$; for the comparison, $N=66$. Boldface values indicate the group that scored highest in each domain.

\begin{tabular}{|c|c|}
\hline Scale & $M_{\text {Autism }}\left(\mathrm{SD}_{\text {Autism }}\right) \mid M_{\text {Comparison }}\left(\mathrm{SD}_{\text {Comparison }}\right)$ \\
\hline Attention to weather and weather information & $29.67(6.83) \mid 28.89(7.15)$ \\
\hline Sensing and direct observation of weather & $19.62(3.71) \mid 18.41(3.67)$ \\
\hline Effects of weather on daily activities & $9.58(2.66) \mid 9.48(2.79)$ \\
\hline Attachment to weather patterns & $\mathbf{9 . 0 8}(3.97) \mid 8.52(3.70)$ \\
\hline Effects of weather on mood & $21.51(5.17) \mid 21.02(5.38)$ \\
\hline Need for weather variability & $12.45(4.08) \mid 11.88(3.99)$ \\
\hline Attention to weather-induced holiday & $11.02(3.20) \mid \mathbf{1 1 . 2 3}(2.85)$ \\
\hline Total weather salience & $\mathbf{9 8 . 9 3}(16.99) \mid 95.97(18.37)$ \\
\hline
\end{tabular}


TABLE 7. Descriptive statistics for WxSQ subscales by group, from S2. For autism, $N=104$; for the comparison, $N=58$. Boldface values indicate the group that scored highest in each domain.

\begin{tabular}{lc}
\hline \hline \multicolumn{1}{c}{ Scale } & $M_{\text {Autism }}\left(\mathrm{SD}_{\text {Autism }}\right) \mid M_{\text {Comparison }}\left(\mathrm{SD}_{\text {Comparison }}\right)$ \\
\hline Attention to weather and weather information & $\mathbf{2 0 . 1 4}(7.15) \mid 18.86(6.76)$ \\
Sensing and direct observation of weather & $\mathbf{8 . 8 1}(3.46) \mid 8.59(2.99)$ \\
Effects of weather on daily activities & $7.27(3.29) \mid \mathbf{7 . 4 7}(2.92)$ \\
Attachment to weather patterns & $\mathbf{9 . 1 5}(4.03) \mid 8.05(3.94)$ \\
Effects of weather on mood & $12.25(5.73) \mid \mathbf{1 2 . 6 6}(5.54)$ \\
Need for weather variability & $\mathbf{1 0 . 7 7}(4.41) \mid 10.43(4.32)$ \\
Attention to weather-induced holiday & $\mathbf{5 . 9 0}(3.57) \mid 5.57(2.87)$ \\
Total weather salience & $\mathbf{6 4 . 1 6}(16.30) \mid 62.39(15.14)$ \\
\hline
\end{tabular}

Chaos also appears to describe the difficulty autistic people have in mentally modeling social systems. While some social situations may be well scripted, such as in a dance or theatre performance, real-world emotions are generally not; rather, they are highly unpredictable and quickly become untenable from a systemizing perspective. Emotions are multifaceted and changes in dynamic affective ${ }^{4}$ systems over time occur as different individual components within the affect system mutually influence one another (e.g., in a nonlinear fashion). We can understand this through a thought experiment: Think about the ways even "simple" conversation can flow and quickly change from one topic to the next. Now, try to imagine how it might be for someone with difficulties in cognitive empathizing_inhibited in accurately assessing another person's thoughts, emotions, and intentions - to read and predict, from a fleeting expression, tonal fluctuation, or change in body language, the potential directions a conversation might take. To be most successful in communication, the systemizing socializer needs to know and accurately predict an innumerable ensemble of potential responses in any given interaction. This is why systemizing is suboptimal when applied to social settings: The systemizing socializer might expect response A but instead get response $\mathrm{C}, \mathrm{D}, \mathrm{H}$, or $\mathrm{T}$ - each further from their original predicted outcome and, thus, ever more confusing to interpret through systemizing and within the context of the interaction: in essence, chaos.

Because of weaknesses in cognitive empathizing, some autistic people might be more inclined to systemize socially, in face of the fact that the chaotic nature of social interactions can impair the success of this strategy. The difficulties demonstrated in the thought experiment above might then result for them in anxiety related to a struggle to

\footnotetext{
${ }^{4}$ Affect is the term used to represent one's place on the spectrum of attitudes and emotional and mental states. Positive affect refers to the pleasant side of these (e.g., feeling grateful), while negative affect references the unpleasant side (e.g., feeling contemptuous or irritable).
}

understand the intent of people in the conversation (BaronCohen 2000; Kinderman et al. 1998), and other negative outcomes related to the misattribution of mental states (e.g., misunderstanding of conversational cues) may further reinforce these issues. These issues are not unique to autistic individuals - even for some nonautistic individuals, predicting these changes accurately can result in similar anxiety. Ironically, this emotional factor hints that science communication can benefit by approaching perceived randomness from chaotic systems more with empathy and less from a systemizing (or strictly scientific) standpoint.

Perception of the appearance of randomness and tolerance for perceived randomness appear to be important factors in understanding the weather salience/systemizing relationship. Past literature helps support this idea. Research has shown that perceptions of randomness can be biased (Falk and Konold 1997; Kareev 1992; Kahneman and Tversky 1972; Tversky 1974) and are unique to each individual (Hahn and Warren 2009). They might also be situation dependent (e.g., the expectation of equal outcomes in a coin flip appears predicated on a focus for proportions rather than specific orders; Kareev 1992). We believe that this avenue of thought is worthy of future research, particularly when seeking to advance understanding of individual weather salience within the context of the systemizing and chaos theories. A randomness threshold of some type may help to identify effective communication methods, better explain the systemizability of meteorological phenomena, and enable a more concrete understanding of the factors underlying an individual's resulting salience toward that phenomenon.

Along these lines of thought, we expect that people strongest in the drive to systemize may have difficulty meaningfully processing weather information or may process it very rigidly. If one is a hypersystemizer, weather will very likely appear as a system that contains too much variance for the individual to process successfully (Baron-Cohen 2008). An individual's threshold for randomness may be dependent upon a number of factors, including the geographical location of the individual, their own experiences with weather, or the weather type 
(and therefore the temporal-spatial scale) being observed. As a result, hypersystemizers may especially poorly estimate the variance inherent within the atmospheric system-an issue that can occasionally stress even experienced weather forecasters. However, although weather may appear to be too complex or random for hypersystemizers to fully engage with it, autistic individuals who are interested in weather may be especially likely to be fascinated by the meteorological field (even hypersystemizers whose interests may be at a conceptually lower level but nonetheless present). Perhaps these individuals are intrigued on some level by the fact that weather can continually and unexpectedly deviate from and force revision of various internal meteorological rules.

This final idea is hinted at in our results and could be taken advantage of in weather outreach scenarios. Studies 1 and 3 found interest in weather and desire to become meteorologists higher among autistic participants, while autistic participants in study 2 reported less self-perceived interest but were nonetheless more salient than the nonautistic participants. This latter finding could reflect an aspect of hypersystemizing whereby the individual is less interested in weather from a systems preference standpoint but becomes more salient from a systems ability standpoint when actually interested. When asked about weather's likeability, the autistic participants indicated weather's predictability and suitability for categorization more often than other factors, such as liking weather for its beauty, compared to the nonautistic participants (though beauty was also high in the autism samples). These findings are relevant to the WRN initiative: In learning contexts, it may seem an autistic individual is not interested when lectured to about a particular topic; but, when engaged through hands-on demonstration or with another topic, they may suddenly display an enhanced awareness and or/interest for that activity or topic. We conclude by suggesting that some autistic populations may engage better with more technical details of the weather in outreach settings, particularly with respect to different rules (e.g., safety).

Altogether, our results hint that autistic individuals may be uniquely attuned to weather's predictability challenges. Further investigation is needed to better understand the weather salience-chaos relationship and the motivations and abilities involved in systemizing weather. Research using chaos theory as an interpretive framework may reveal information about strategies used in systemizing and help to motivate a reassessment of the systemizing concept.

\section{Conclusions}

This paper reports the first empirical examination of weather salience in autism. Findings suggest that weather salience is higher, on average, in autistic individuals. This appears related to the systemizing mechanism that is thought to be naturally tuned to a higher level in autism. Findings also suggest that weather is a special interest topic for autistic people, and that autistic individuals exhibit, via self-report, higher interest in weather and desire to become meteorologists compared to nonautistic individuals. The consideration of chaos theory in this work posits a possible unified psychological framework of weather salience, systemizing, and chaos to enable a more rounded understanding for how individuals engage with weather information. Such a framework could be applied not only within a weather-salience perspective but also those geared toward communication [e.g., social network analysis (Clifton and Webster 2017) and the ways that weather information flows between people].

\section{Limitations and future work}

These studies were limited by small online survey samples. Thus, statistical power was problematic and participant honesty and other impression management concerns, attention to and/or understanding of questions, and accuracy of self-awareness all could affect the data. Further, a selection bias may be induced by virtue of autism's heterogeneity, self-report, and the autismweather relationship, whereby our samples could be composed of people more attuned to, and interested in, weather from the outset, so that the samples reflect the most weather-salient and functionally able autistic people. Work to further investigate the weathersystemizing relationship and to understand potential linkages between physiological sensitivity to weather and autism is being undertaken in both general and autistic population samples. These projects, the start of applied work in the area, are attempting replication of the between-group weather-salience/systemizing results reported here. Other autism-weather work could involve task performance and observation to help mitigate impression management concerns.

Neuroimaging research would also help elucidate potential weather-autism interactions as well as reveal ways people are affected by and respond to weather more generally. Preliminary autism work (see Baron-Cohen and Lombardo 2017) has found possible connections between attention to detail and activation of the occipital cortex and lateral frontoparietal circuit; these areas may also be of interest in relation to weather salience.

Acknowledgments. We are grateful to all who volunteered for our studies to help us advance life-benefiting knowledge. We are also grateful to Cathy Dionne at the Autism Society of Maine for assistance in distributing the first survey and to Paula Smith at the Autism Research 
Centre, Cambridge, for distributing the second and third surveys. Last, we are grateful to Hannah Aizenman for assistance with Python code to generate our figure, and we thank Sean Ernst for reviewing a late draft of this paper. We collectively thank Traci Blumberg for valuable discussion over the course of writing the paper. Authors Bolton, Blumberg, and Mogil formulated the hypotheses. Bolton conceived and designed the studies under the supervision of author Ault and with the assistance of authors Hanes and Mogil. Hanes also facilitated contact with the Autism Society of Maine. Bolton and Ault analyzed and interpreted the data. Bolton and Blumberg wrote the paper with support from Ault; all authors approved the final paper. This work was conducted without funding. We have no conflicts of interest to declare. Open data and materials are available online (https://osf.io/xzn7a/).

\section{REFERENCES}

Agelink van Rentergem, J. A., A. G. Lever, and H. M. Geurts, 2019: Negatively phrased items of the Autism Spectrum Quotient function differently for groups with and without autism. Autism, 23, 1752-1764, https://doi.org/10.1177/ 1362361319828361.

Altman, I., and S. M. Low, Eds., 1992: Place attachment. Human Behavior and Environment: Advances in Theory and Research, Plenum Press, 1-12.

American Psychiatric Association, 2013: Autism spectrum disorder. Diagnostic and Statistical Manual of Mental Disorders: DSM-5. American Psychiatric Association, 50-59.

Attwood, T., 2003: Understanding and managing circumscribed interests. Learning and Behaviour Problems in Asperger Syndrome, M. Prior, Ed., Guilford Press, 126-147.

Baez, S., D. Flichtentrei, M. Prats, R. Mastandueno, A. M. García, M. Cetkovich, and A. Ibáñez, 2017: Men, women. . .who cares? A population-based study on sex differences and gender roles in empathy and moral cognition. PLOS ONE, 12, e0179336, https://doi.org/10.1371/journal.pone.0179336.

Baron-Cohen, S., 2000: Autism and 'theory of mind'. The Applied Psychologist, 2nd ed. J. Hartley and A. Branthwaite, Eds., Open University Press, 181-194.

— 2003: The Essential Difference: The Truth about the Male and Female Brain. Penguin/Basic Books, 271 pp.

_- 2006: The hyper-systemizing, assortative mating theory of autism. Prog. Neuropsychopharmacol. Biol. Psychiatry, 30, 865-872, https://doi.org/10.1016/j.pnpbp.2006.01.010.

- 2008: Autism, hypersystemizing, and truth. Quart. J. Exp. Psychol., 61, 64-75, https://doi.org/10.1080/17470210701508749.

- 2009: Autism: The empathizing-systemizing (E-S) theory. Ann. N. Y. Acad. Sci., 1156, 68-80, https://doi.org/10.1111/ j.1749-6632.2009.04467.x.

_ 2015: Autism, maths, and sex: The special triangle. Lancet Psychiatry, 2, 790-791, https://doi.org/10.1016/S2215-0366(15) 00397-1.

_ - 2017: Editorial perspective: Neurodiversity-A revolutionary concept for autism and psychiatry. J. Child Psychol. Psychiatry, 58, 744-747, https://doi.org/10.1111/jcpp.12703.

—_, and S. Wheelwright, 2004: The empathy quotient: An investigation of adults with Asperger syndrome or high functioning autism, and normal sex differences. J. Autism Dev. Disord., 34, 163-175, https://doi.org/10.1023/B:JADD. 0000022607.19833.00.

— , and M. V. Lombardo, 2017: Autism and talent: The cognitive and neural basis of systemizing. Dialogues Clin. Neurosci., 19, $345-352$.

—, A. M. Leslie, and U. Frith, 1986: Mechanical, behavioral and intentional understanding of picture stories in autism children. Br. J. Dev. Psychol., 4, 113-125, https://doi.org/ 10.1111/j.2044-835X.1986.tb01003.x.

_ S. Wheelwright, C. Stott, P. Bolton, and I. Goodyer, 1997: Is there a link between engineering and autism? Autism, 1, 101109, https://doi.org/10.1177/1362361397011010.

_ , P. Bolton, S. Wheelwright, V. Scahill, L. Short, G. Mead, and A. Smith, 1998: Does autism occur more often in families of physicists, engineers, and mathematicians? Autism, 2, 296301, https://doi.org/10.1177/1362361398023008.

, S. Wheelwright, V. Stone, and M. Rutherford, 1999: A mathematician, a physicist, and a computer scientist with Asperger syndrome: Performance on folk psychology and folk physics tests. Neurocase, 5, 475-483, https://doi.org/10.1080/ 13554799908402743.

,,-- V. Scahill, A. Spong, and J. Lawson, 2001a: Studies of theory of mind: Are intuitive physics and intuitive psychology independent? J. Dev. Learn. Disord., 5, 47-78, http:/ docs.autismresearchcentre.com/papers/2001_BCetal_kidseyes.pdf.

,-- , R. Skinner, J. Martin, and E. Clubley, 2001b: The Autism Spectrum Quotient (AQ): Evidence from Asperger syndrome/high functioning autism, males and females, scientists and mathematicians. J. Autism Dev. Disord., 31, 5-17, https://doi.org/10.1023/A:1005653411471.

_ J. Richler, D. Bisarya, N. Gurunathan, and S. Wheelwright, 2003: The systemizing quotient: An investigation of adults with Asperger syndrome or high-functioning autism, and normal sex differences. Philos. Trans. Roy. Soc. London, B358, 361-374, https://doi.org/10.1098/rstb.2002.1206.

- S. Wheelwright, A. Burtenshaw, and E. Hobson, 2007: Mathematical talent is linked to autism. Hum. Nat., 18, 125131, https://doi.org/10.1007/s12110-007-9014-0.

- - E. Ashwin, C. Ashwin, T. Tavassoli, and B. Chakrabarti, 2009: Talent in autism: Hyper-systemizing, hyper-attention to detail and sensory hypersensitivity. Philos. Trans. Roy. Soc. London, B364, 1377-1383, https://doi.org/10.1098/ rstb.2008.0337.

Bashe, P. R., and B. L. Kirby, 2001: What Asperger syndrome looks like. The OASIS Guide to Asperger Syndrome: Advice, Support, Insight, and Inspiration, B. L. Kirby and P. R. Bashe, Eds., Crown Publishers, 39-63.

Billington, J., S. Baron-Cohen, and S. Wheelwright, 2007: Cognitive style predicts entry into physical sciences and humanities: Questionnaire and performance tests of empathy and systemizing. Learn. Individ. Differ., 17, 260-268, https://doi.org/10.1016/j.lindif.2007.02.004.

Bolton, M. J., and H. M. Mogil, 2018: Revisiting the color conundrum: On the use of color in weather displays. Sixth Symp. on Building a Weather-Ready Nation: Enhancing Our Nation, Austin, TX, Amer. Meteor. Soc., 7.2, https://ams.confex.com/ ams/98Annual/webprogram/Paper332386.html.

—_, W. G. Blumberg, and H. M. Mogil, 2017: An analysis of the characteristics of autism spectrum conditions for application to weather communication methods in the weather enterprise. OSF Preprints 42 pp., https://doi.org/10.17605/ OSF.IO/TNA3X. 
L. K. Ault, D. M. Greenberg, and S. Baron-Cohen, 2018a: Exploring the human side of meteorology: A brief report on the psychology of meteorologists. J. Oper. Meteor., 6, 23-32, https://doi.org/10.15191/NWAJOM.2018.0603.

_ , H. M. Mogil, G. T. Harvey, and L. K. Ault, 2018b: Rainfall estimation skill and links between weather salience and detail orientation. Bull. Amer. Meteor. Soc., 99, 2226-2227, https:// doi.org/10.1175/BAMS_9911_2211-2228_Nowcast.

Bonnel, A., L. Mottron, I. Peretz, M. Trudel, E. Gallun, and A. M. Bonnel, 2003: Enhanced pitch sensitivity in individuals with autism: A signal detection analysis. J. Cogn. Neurosci., 15, 226-235, https://doi.org/10.1162/089892903321208169.

— S. McAdams, B. Smith, C. Berthiaume, A. Bertone, V. Ciocca, J. A. Burack, and L. Mottron, 2010: Enhanced pure-tone pitch discrimination among persons with autism but not Asperger syndrome. Neuropsychologia, 48, 2465-2475, https://doi.org/ 10.1016/j.neuropsychologia.2010.04.020.

Boslaugh, S., 2012: Statistics in a Nutshell: A Desktop Quick Reference. 2nd ed. O'Reilly Media Inc., 375 pp.

Braun, V., and V. Clarke, 2006: Using thematic analysis in psychology. Qual. Res. Psychol., 3, 77-101, https://doi.org/10.1191/ 1478088706qp063oa.

Buescher, A. V. S., Z. Cidav, M. Knapp, and D. S. Mandell, 2014: Costs of autism spectrum disorders in the United Kingdom and the United States. JAMA Pediatr., 168, 721-728, https:// doi.org/10.1001/jamapediatrics.2014.210.

Caldwell-Harris, C. L., and C. J. Jordan, 2014: Systemizing and special interests: Characterizing the continuum from neurotypical to autism spectrum disorder. Learn. Individ. Differ., 29, 98-105, https://doi.org/10.1016/j.lindif.2013.10.005.

Campbell, J. M., 1983: Ambient stressors. Environ. Behav., 15, 355-380, https://doi.org/10.1177/0013916583153005.

Caron, M. J., L. Mottron, C. Berthiaume, and M. Dawson, 2006: Cognitive mechanisms, specificity and neural underpinnings of visuospatial peaks in autism. Brain, 129, 1789-1802, https:// doi.org/10.1093/brain/awl072.

CBC News, 2013: Cape Breton amateur weather man is a viral video star. http://www.cbc.ca/news/canada/nova-scotia/capebreton-amateur-weather-man-is-a-viral-video-star-1.1342904.

Clifton, A., and G. D. Webster, 2017 An introduction to social network analysis for personality and social psychologists. Soc. Psychol. Pers. Sci., 8, 442-453, https://doi.org/10.1177\% 2F1948550617709114.

Coleman, J. S. M., K. D. Newby, K. D. Multon, and C. L. Taylor, 2014: Weathering the storm: Revisiting severe-weather phobia. Bull. Amer. Meteor. Soc., 95, 1179-1183, https://doi.org/ 10.1175/BAMS-D-13-00137.1.

Cronbach, L. J., 1951: Coefficient alpha and the internal structure of tests. Psychometrika, 16, 297-334, https://doi.org/10.1007/ BF02310555.

Dakin, S., and U. Frith, 2005: Vagaries of visual perception in autism. Neuron, 48, 497-507, https://doi.org/10.1016/j.neuron.2005.10.018.

Danforth, C. M., 2015: Chaos in an atmosphere hanging on a wall. Mathematics of Planet Earth, http://mpe.dimacs.rutgers.edu/ 2013/03/17/chaos-in-an-atmosphere-hanging-on-a-wall/.

Delacre, M., C. Leys, Y. L. Mora, and D. Lakens, 2019: Taking parametric assumptions seriously: Arguments for the use of Welch's $F$-test instead of the classical $F$-test in one-way ANOVA. Int. Rev. Soc. Psychol., 32, 13, http://doi.org/10.5334/irsp.198.

Drake, J. E., A. Redash, K. Coleman, J. Haimson, and E. Winner, 2010: "Autistic" local processing bias also found in children gifted in realistic drawing. J. Autism Dev. Disord., 40, 762-773, https://doi.org/10.1007/s10803-009-0923-0.
Evans, G. W., and S. Cohen, 1987: Environmental stress. Handbook of Environmental Psychology, D. Stokols and I. Altman, Eds., John Wiley and Sons, 571-610.

Falk, R., and C. Konold, 1997: Making sense of randomness: Implicit encoding as a basis for judgment. Psychol. Rev., 104, 301-318, https://doi.org/10.1037/0033-295X.104.2.301.

Fells, J., 2013: 'Konfirmation systemization', Jon Adams: Systematic art-Revaluing autistic thinking. Arts Catalyst, 32 pp., https:// www.artscatalyst.org/sites/default/files/project_attachments/ Jon \%20Adams \%20Konfirm \%20-\%20final\%20evaluation \% 20 report $\% 20 \% 28$ reduced $\% 20$ file $\% 20$ size $\% 29$.pdf.

Gartner, L., 2014: Boy with Asperger syndrome finds calling as a weatherman calming. Tampa Bay Times, http://www.tampabay.com/ news/education/k12/boy-with-asperger-syndrome-finds-callingas-weatherman-calming/2205610.

Greenberg, D. M., P. J. Rentfrow, and S. Baron-Cohen, 2015a: Can music increase empathy? Interpreting musical experience through the empathizing-systemizing (E-S) theory: Implications for autism. Empirical Musicol. Rev., 10, 80-95. S. Baron-Cohen, D. J. Stillwell, M. Kosinski, and P. J. Rentfrow, 2015b: Musical preferences are linked to cognitive styles. PLOS ONE, 10, e0131151, https://doi.org/10.1371/ journal.pone.0131151.

Grove, R., R. A. Hoekstra, M. Wierda, and S. Begeer, 2018: Special interests and subjective wellbeing in autistic adults. Autism Res., 11, 766-775, https://doi.org/10.1002/aur.1931.

Guastello, S. J., and L. S. Liebovitch, 2009: Introduction to nonlinear dynamics and complexity. Chaos and Complexity in Psychology: The Theory of Nonlinear Dynamical Systems, S. J. Guastello, M. Koopmans, and D. Pincus, Eds., Cambridge University Press, 1-40.

Hahn, U., and P. A. Warren, 2009: Perceptions of randomness: Why three heads are better than four. Psychol. Rev., 116, 454461, https://doi.org/10.1037/a0015241.

Happé, F., 1999: Autism: Cognitive deficit or cognitive style. Trends Cogn. Sci., 3, 216-222, https://doi.org/10.1016/S13646613(99)01318-2.

, and U. Frith, 2006: The weak central coherence account: Detail-focused cognitive style in autism spectrum disorders. J. Autism Dev. Disord., 36, 5-25, https://doi.org/10.1007/ s10803-005-0039-0.

- , and P. Vital, 2009: What aspects of autism predispose to talent? Philos. Trans. Roy. Soc. London, B364, 1369-1375, https://doi.org/10.1098/rstb.2008.0332.

Heaton, P., 2003: Pitch memory, labelling, and disembedding in autism. J. Child Psychol. Psychiatry, 44, 543-551, https:// doi.org/10.1111/1469-7610.00143.

2005: Interval and contour processing in autism. J. Autism Dev. Disord., 35, 787-793, https://doi.org/10.1007/s10803-0050024-7.

- 2009: Assessing musical skills in autistic children who are not savants. Philos. Trans. Roy. Soc. London, B364, 1443-1447, https://doi.org/10.1098/rstb.2008.0327.

Heavey, L., L. Pring, and B. Hermelin, 1999: A date to remember: The nature of memory in savant calendrical calculators. Psychol. Med., 29, 145-160, https://doi.org/10.1017/S0033291798007776.

Jarrold, C., I. D. Gilchrist, and A. Bender, 2005: Embedded figures detection in autism and typical development: Preliminary evidence of a double dissociation in relationships with visual search. Dev. Sci., 8, 344-351, https://doi.org/10.1111/j.14677687.2005.00422.x.

Jordan, C. J., and C. L. Caldwell-Harris, 2012: Understanding differences in neurotypical and autism spectrum special interests 
through internet forums. Intellect. Dev. Disabil., 50, 391-402, https://doi.org/10.1352/1934-9556-50.5.391.

Joseph, R. M., B. Keehn, C. Connolly, J. M. Wolfe, and T. S. Horowitz, 2009: Why is visual search superior in autism spectrum disorder? Dev. Sci., 12, 1083-1096, https://doi.org/10.1111/ j.1467-7687.2009.00855.x.

Kahneman, D., and A. Tversky, 1972: Subjective probability: A judgment of representativeness. Cognit. Psychol., 3, 430-454, https://doi.org/10.1016/0010-0285(72)90016-3.

Kareev, Y., 1992: Not that bad after all: Generation of random sequences. J. Exp. Psychol. Hum. Percept. Perform., 18, 11891194, https://doi.org/10.1037/0096-1523.18.4.1189.

Keehn, B., P. Shih, L. A. Brenner, J. Townsend, and R.-A. Müller, 2012: Functional connectivity for an "island of sparing" in autism spectrum disorder: An fMRI study of visual search. Hum. Brain Mapp., 34, 2524-2537, https://doi.org/10.1002/ hbm.22084.

Kidron, R., L. Kaganovsk, and S. Baron-Cohen, 2018: Empathizingsystemizing cognitive styles: Effects of sex and academic degree. PLOS ONE, 13, e0194515, https://doi.org/10.1371/ journal.pone.0194515.

Kinderman, P., R. Dunbar, and R. P. Bentall, 1998: Theory-ofmind deficits and causal attributions. Br. J. Psychol., 89, 191204, https://doi.org/10.1111/j.2044-8295.1998.tb02680.x.

Klin, A., J. H. Danovitch, A. B. Merz, and F. R. Volkmar, 2007: Circumscribed interests in higher functioning individuals with autism spectrum disorders: An exploratory study. Res. Pract. Persons Severe Disabl., 32, 89-100, https://doi.org/10.2511\% 2FRPSD.32.2.89.

Knez, I., 2005: Attachment and identity as related to a place and its perceived climate. J. Environ. Psychol., 25, 207-218, https:// doi.org/10.1016/j.jenvp.2005.03.003.

Kozhevnikov, M., 2007: Cognitive styles in the context of modern psychology: Towards an integrated framework of cognitive styles. Psychol. Bull., 133, 464-481, https://doi.org/10.1037/ 0033-2909.133.3.464.

Lawson, J., S. Baron-Cohen, and S. Wheelwright, 2004: Empathising and systemising in adults with and without Asperger syndrome. J. Autism Dev. Disord., 34, 301-310, https://doi.org/10.1023/B: JADD.0000029552.42724.1b.

Levine, T. R., and C. R. Hullett, 2002: Eta squared, partial eta squared, and misreporting of effect size in communication research. Hum. Commun. Res., 28, 612-625, https://doi.org/ 10.1111/j.1468-2958.2002.tb00828.x.

Ling, J., T. C. Burton, J. L. Salt, and S. J. Muncer, 2009: Psychometric analysis of the Systemizing Quotient (SQ) scale. Br. J. Psychol., 100, 539-552, https://doi.org/10.1348/ 000712608 X368261.

Litman, J. A., and C. D. Spielberger, 2003: Measuring epistemic curiosity and its diversive and specific components. J. Pers. Assess., 80, 75-86, https://doi.org/10.1207/S15327752JPA8001_16.

Lorenz, E., 1963: Deterministic nonperiodic flow. J. Atmos. Sci., 20, 130-141, https://doi.org/10.1175/1520-0469(1963)020<0130: $\mathrm{DNF}>2.0 . \mathrm{CO} ; 2$.

_ 1964: The problem of deducing the climate from the governing equations. Tellus, 16, 1-11, https://doi.org/10.3402/ tellusa.v16i1.8893.

, 1993: The Essence of Chaos. University of Washington Press, $227 \mathrm{pp}$

Mancil, G. R., and C. E. Pearl, 2008: Restricted interests as motivators: Improving academic engagement and outcomes of children on the autism spectrum. Teach. Exceptional Child. Plus, 4, EJ967728, https://files.eric.ed.gov/fulltext/EJ967728.pdf.
Masi, A., M. M. DeMayo, N. Glozier, and A. J. Guastella, 2017: An overview of autism spectrum disorder, heterogeneity and treatment options. Neurosci. Bull., 33, 183-193, https:// doi.org10.1007/s12264-017-0100-y.

Moore, V., and S. Goodson, 2003: How well does early diagnosis of autism stand the test of time? Follow-up study of children assessed for autism at age 2 and development of an early diagnostic service. Autism, 7, 47-63, https://doi.org/10.1177/ 1362361303007001018.

Mottron, L., S. Belleville, and E. Stip, 1996: Proper name hypermnesia in an autistic subject. Brain Lang., 53, 326-350, https://doi.org/10.1006/brln.1996.0052.

— , M. Dawson, I. Soulières, B. Hubert, and J. Burack, 2006: Enhanced perceptual functioning in autism: An update, and eight principles of autistic perception. J. Autism Dev. Disord., 36, 27-43, https://doi.org/10.1007/s10803-005-0040-7.

National Weather Service, 2016: Deaf-and-hard-of-hearing lightning safety PSA. YouTube, https://www.youtube.com/watch? $\mathrm{v}=\mathrm{uU} 11 \mathrm{O} 1 \mathrm{~S} 15 \mathrm{e} 4 \&$ feature $=$ youtu.be.

Neil, L., N. C. Olsson, and E. Pellicanono, 2016: The relationship between intolerance of uncertainty, sensory sensitivities, and anxiety in autistic and typically developing children. J. Autism Dev. Disord., 46, 1962-1973, https://doi.org/10.1007/s10803-016-2721-9.

Newman, J., 2014: To Siri, with love. New York Times, 19 October, ST, http://www.nytimes.com/2014/10/19/fashion/how-applessiri-became-one-autistic-boys-bff.html.

O'Riordan, M. A., 2004: Superior visual search in adults with autism. Autism, 8, 229-248, https://doi.org/10.1177/1362361304045219.

_ , K. C. Plaisted, J. Driver, and S. Baron-Cohen, 2001: Superior visual search in autism. J. Exp. Psychol. Hum. Percept. Perform., 27, 719-730, https://doi.org/10.1037/0096-1523.27.3.719.

Plaisted, K., M. O'Riordan, and S. Baron-Cohen, 1998: Enhanced visual search for a conjunctive target in autism: A research note. J. Child Psychol. Psychiatry, 39, 777-783, https://doi.org/ 10.1111/1469-7610.00376.

Pring, L., and B. Hermelin, 2002: Numbers and letters: Exploring an autistic savant's unpractised ability. Neurocase, $\mathbf{8}, 330-337$, https://doi.org/10.1076/NEUR.8.3.330.16193.

,-- , and L. Heavey, 1995: Savants, segments, art and autism. J. Child Psychol. Psychiatry, 36, 1065-1076, https://doi.org/ 10.1111/j.1469-7610.1995.tb01351.x.

Reeb, J. L., 2017: Keynote address on weather communication and vulnerable populations. 42nd Annual Meeting, Garden Grove, CA, National Weather Association.

Roelfsema, M. T., R. A. Hoekstra, C. Allison, S. Wheelwright, C. Brayne, F. E. Matthews, and S. Baron-Cohen, 2011: Are autism spectrum conditions more prevalent in an informationtechnology region? A school-based study of three regions in The Netherlands. J. Autism Dev. Disord., 42, 734-739, https:// doi.org/10.1007/s10803-011-1302-1.

Ruzich, E., C. Allison, B. Chakrabarti, P. Smith, H. Musto, H. Ring, and S. Baron-Cohen, 2015: Sex and STEM occupation predict Autism-Spectrum Quotient (AQ) scores in half a million people. PLOS ONE, 10, e0141229, https://doi.org/ 10.1371/journal.pone.0141229.

Sherman-Morris, K., and T. Pechacek, 2018: Tornado warning communication needs among the blind/low-vision community. 43rd Annual Meeting, Saint Louis, MO, National Weather Association, 212, https://objects-us-east-1.dream.io/nwafiles/ Annual\%20Meetings/2018/Abstracts/Tornado\%20warning \% 20communication $\% 20$ needs $\% 20$ among $\% 20$ the $\% 20$ Blind.htm.

Silani, G., G. Bird, R. Brindley, T. Singer, C. Frith, and U. Frith, 2008: Levels of emotional awareness and autism: An fMRI 
study. Soc. Neurosci., 3, 97-112, https://doi.org/10.1080/ 17470910701577020.

Stewart, A. E., 2009: Minding the weather: The measurement of weather salience. Bull. Amer. Meteor. Soc., 90, 1833-1842, https://doi.org/10.1175/2009BAMS2794.1.

—_ 2017: Assessing weather curiosity in university students. 2017 Fall Meeting, San Francisco, CA, Amer. Geophys. Union, Abstract ED31A-0277, https://ui.adsabs.harvard.edu/abs/ 2017AGUFMED31A0277S/abstract.

— J. K. Lazo, R. E. Morss, and J. L. Demuth, 2012: The relationship of weather salience with the perceptions and uses of weather information in a nationwide sample of the United States. Wea. Climate Soc., 4, 172-189, https://doi.org/10.1175/ WCAS-D-11-00033.1.

Stokols, D., 1985: A congruence analysis of human stress. Issues Ment. Health Nurs., 7, 35-64, https://doi.org/10.3109/01612848509009449.

Svedholm-Häkkinen, A. M., and M. Lindeman, 2016: Testing the empathizing-systemizing theory in the general population: Occupations, vocational interests, grades, hobbies, friendship quality, social intelligence, and sex role identity. Pers. Ind. Differ., 90, 365-370, https://doi.org/10.1016/j.paid.2015.11.044.

Szucs, D., and J. P. A. Ioannidis, 2017: Empirical assessment of published effect sizes and power in the recent cognitive neuroscience and psychology literature. PLOS Biol., 15, e2000797, https://doi.org/10.1371/journal.pbio.2000797.

Taylor, S. E., and S. T. Fiske, 1979: Salience, attention, and attribution: Top of the head phenomena. Advances in Experimental Social Psychology, L. Berkowitz, Ed., Vol. 11, Academic Press, 249-288.

Turner-Brown, L. M., K. S. L. Lam, T. N. Holtzclaw, G. S. Dichter, and J. W. Bodfish, 2011: Phenomenology and measurement of circumscribed interests in autism spectrum disorders. Autism, 15, 437-456, https://doi.org/10.1177/1362361310386507.
Tversky, A., 1974: Assessing uncertainty. J. Roy. Stat. Soc., 36B, 148-159, https://doi.org/10.1111/J.2517-6161.1974.TB00996.X.

U.S. Centers for Disease Control, 2018: Autism prevalence slightly higher in CDC's ADDM Network. CDC, https://www.cdc.gov/ media/releases/2018/p0426-autism-prevalence.html.

Wakabayashi, A., S. Baron-Cohen, S. Wheelwright, N. Goldenfeld, J. Delaney, D. Fine, R. Smith, and L. Weil, 2006: Development of short forms of the Empathy Quotient (EQ-short) and the Systemizing Quotient (SQ-short). Pers. Ind. Diffs., 41, 929940, https://doi.org/10.1016/j.paid.2006.03.017.

Warrier, V., and Coauthors, 2019: Social and non-social autism symptoms and trait domains are genetically dissociable. Commun. Biol., 2, 328, https://doi.org/10.1038/s42003019-0558-4.

Wheelwright, S., and S. Baron-Cohen, 2001: The link between autism and skills such as engineering, maths, physics and computing: A reply to Jarrold and Routh, Autism, 1998, 2(3): 281-9. Autism, 5, 223-227, https://doi.org/10.1177/ 1362361301005002010.

, — , N. Goldenfeld, J. Delaney, D. Fine, R. Smith, L. Weil, and A. Wakabayashi, 2006: Predicting Autism Spectrum Quotient (AQ) from the Systemizing Quotient-Revised (SQR) and Empathy Quotient (EQ). Brain Res., 1079, 47-56, https://doi.org/10.1016/j.brainres.2006.01.012.

Young, T. R., 1995: Chaos theory and social dynamics: Foundations of postmodern social science. Chaos Theory in Psychology and the Life Sciences, R. Robertson and A. Combs, Eds., Psychology Press, 217-234.

Zeyer, A., K. Bölsterli, D. Brovelli, and F. Odermatt, 2012: Brain type or sex differences? A structural equation model of the relation between brain type, sex, and motivation to learn science. Int. J. Sci. Educ., 34, 779-802, https://doi.org/10.1080/ 09500693.2011.635165. 